\title{
Choroidal and macular thickness changes induced by cataract surgery
}

\author{
Manuel S Falcão ${ }^{1,2}$ \\ Nuno M Gonçalves ${ }^{2}$ \\ Paulo Freitas-Costa ${ }^{1,3}$ \\ João B Beato \\ Amândio Rocha-Sousa ${ }^{1,2}$ \\ Ângela Carneiro ${ }^{1,2}$ \\ Elisete M Brandão ${ }^{2}$ \\ Fernando M Falcão-Reis ${ }^{1,2}$ \\ 'Department of Sense Organs, Faculty \\ of Medicine, University of Porto, \\ ${ }^{2}$ Department of Ophthalmology of \\ Hospital de São João, ${ }^{3}$ Department \\ of Anatomy, Faculty of Medicine, \\ University of Porto, Porto, Portugal
}

This article was published in the following Dove Press journal:

Clinical Ophthalmology

12 December 2013

Number of times this article has been viewed

Background: The aim of this study was to evaluate the effect of uneventful phacoemulsification on the morphology and thickness of the macula, the submacular choroid, and the peripapillary choroid.

Methods: In 14 eyes from 14 patients, retinal macular thickness, choroidal submacular thickness, and choroidal peripapillary thickness were measured preoperatively and at one week and one month after phacoemulsification using enhanced depth imaging spectral domain optical coherence tomography. Changes in thickness of the different ocular tissues were evaluated.

Results: There was a statistically significant increase in mean retinal macular thickness at one month. In horizontal scans, the mean increase was $+8.67 \pm 6.75 \mu \mathrm{m}(P<0.001)$, and in vertical scans, the mean increase was $+8.80 \pm 7.07 \mu \mathrm{m}(P=0.001)$. However, there were no significant changes in choroidal morphology in the submacular and peripapillary areas one month after surgery. In vertical scans, there was a nonsignificant increase in choroidal thickness $(+4.21 \pm 20.2 \mu \mathrm{m} ; P=0.47)$ whilst in horizontal scans a nonsignificant decrease was recorded $(-9.11 \pm 39.59 \mu \mathrm{m} ; P=0.41)$. In peripapillary scans, a nonsignificant increase in mean choroidal thickness was registered $(+3.25 \pm 11.80 \mu \mathrm{m} ; P=0.36)$.

Conclusion: Uncomplicated phacoemulsification induces nonpathologic increases in retinal macular thickness probably due to the inflammatory insult of the surgery; however these changes are not accompanied by significant changes in choroidal thickness. In the posterior segment, the morphologic response to the inflammatory insult of phacoemulsification is mainly observed at the retinal level, and seems to be independent of choroidal thickness changes.

Keywords: phacoemulsification, macular thickness, choroidal thickness, prostaglandins

\section{Introduction}

Cataract surgery by phacoemulsification is an invasive procedure that has become the most common intraocular surgery and usually improves the visual outcome. However, it is an inflammatory insult to the eye and in many cases can lead to worsening of pre-existing retinal diseases such as diabetic macular edema ${ }^{1,2}$ or development of new diseases such as Irvine-Gass syndrome. ${ }^{3,4}$ This inflammatory response is mostly induced by the release of prostaglandins. ${ }^{5}$

There are not a lot of data regarding the effects of cataract surgery on the posterior segment of the eye. In most cases, phacoemulsification does not change the macroscopic funduscopic appearance of the retina. However, novel noninvasive imaging techniques such as cross-sectional imaging of the retina with time domain and spectral domain optical coherence tomography (SD-OCT) have shown that macular thickness may increase subclinically after surgery. This subclinical thickening can be
Correspondence: Manuel Falcão Department of Sense Organs, Faculty of Medicine, University of Porto, Al Prof Hernâni Monteiro, 4200-3I 9 Porto, Portugal Tel +35 I2 255। 3669 Email falcao@med.up.pt submit your manuscript $\mid$ www.dovepress.com Dovepress 
detected in many cases of uneventful surgery, with a peak occurring 4-6 weeks after surgery. ${ }^{6-10}$ About 6 months after cataract surgery, macular thickness returns to baseline. ${ }^{8}$ The clinical effects of this subclinical increase are not completely known, and in most cases, they probably have no influence on final best-corrected visual acuity. The peripapillary retinal nerve fiber layer has also been shown to increase after cataract surgery, both with SD-OCT ${ }^{11}$ and with scanning laser polarimetry. ${ }^{12}$ Part of these increases may be caused by changes in the optical means of the eye or by an increase in signal strength caused by the surgery.

There are not a lot of biochemical data regarding the effects of cataract surgery on the retina and choroid. Some studies confirm that cataract surgery leads to proinflammatory changes in the posterior segment of the eye. In a rodent model, cataract surgery induced proinflammatory gene expression and protein secretion in the retina and choroid. ${ }^{13}$ Expression of chemokine (C-C motif) ligand 2 and interleukin-1 $\beta$ genes was upregulated in both the retina and choroid and an increase of interleukin- $1 \beta$ expression was observed in the inner nuclear layer, choroid, and ganglion cell layer of operated eyes. Other animal studies showed that cataract surgery led to an increase in macular thickness and a breakdown in the outer blood-retinal barrier in rhesus monkeys. ${ }^{14}$ One other study showed that lenticular fragments could lead to a breakdown of the inner blood-retinal barrier. ${ }^{15}$ These inflammatory consequences of surgery may be associated with the subclinical macular changes that have been reported in uneventful cataract surgery and may also be related to pathologic events such as Irvine-Gass syndrome.

Thus, inflammatory changes occur in the retina and choroid with cataract surgery. However, the morphologic changes that this inflammatory insult produces in the choroid have not yet, to our knowledge, been studied. Until recently, the choroid had been studied mainly with angiography (indocyanine green and fluorescein) or ultrasound. These imaging methods have several limitations for studying choroidal morphology, especially in detecting small changes in thickness. Enhanced depth imaging (EDI) of the choroid using SD-OCT has allowed a greater capacity for evaluating these choroidal changes. ${ }^{16}$ Small changes in choroidal thickness have been assessed using this technology in several pathologic and physiologic conditions. ${ }^{17-20}$

Because cataract surgery is an inflammatory insult to the eye, we investigated the possibility that it may lead to an increase in the choroidal and retinal thickness at the posterior pole and that this eventual increase in choroidal thickness may be related to the changes in retinal macular thickness that have been previously described. Our aim in this study was to evaluate morphologic changes in the macular, choroidal submacular, and peripapillary choroidal tissues caused by uneventful phacoemulsification.

\section{Materials and methods}

This study was approved by the ethics committee of Centro Hospitalar São João, fulfilled all requirements of the Declaration of Helsinki, and was carried out as a prospective interventional cases series in an institutional setting. Fourteen eyes of 14 patients undergoing routine cataract surgery were included. Exclusion criteria included any refractive errors greater than 6 diopters and the presence of any ocular pathology except for cataract. Patients with diabetes mellitus were also excluded. All participants underwent a full ophthalmic examination including visual acuity, slit-lamp evaluation, intraocular pressure measurement by Goldmann tonometry, and macular and optic disc examination to exclude other ocular pathologies.

Preoperatively, the patients underwent EDI SD-OCT using the Spectralis ${ }^{\circledR}$ Heidelberg ${ }^{\circledR}$ apparatus (Heidelberg Engineering, Carlsbad, CA, USA). In each patient, two perpendicular (horizontal and vertical) OCT EDI B-scans averaged 100 times, centered on the fovea, and one peripapillary scan using the default glaucoma application and the preset circular retinal nerve fiber layer scan, consisting of 100 averaged EDI B-scans were obtained.

These scans were marked as the patient's baseline and were used for referencing the subsequent scans using the "follow-up" function of the Spectralis Heidelberg, assuring us that the scans would be performed in the same position. The scans were repeated postoperatively one week and 4 weeks after surgery.

In the horizontal and vertical macular scans, measurements of retinal and choroidal thickness were performed manually using the calipers provided by the Spectralis Heidelberg software on the center of the fovea and $500 \mu \mathrm{m}$, $1,000 \mu \mathrm{m}$, and 1,500 $\mu \mathrm{m}$ away from the fovea in the cardinal directions (vertical, horizontal, nasal, and temporal). A mean of these five values was calculated in order to obtain mean horizontal and mean vertical retinal and choroidal thicknesses. Retinal thickness was measured from the inner limiting membrane to the outer boundary of the retinal pigment epithelium. Choroidal thickness was measured from the outer limit of the retinal pigment epithelium to the choroidal-scleral junction (Figure 1).

In the peripapillary scans, retinal nerve fiber layer thickness was measured automatically using the software provided by the Spectralis Heidelberg. Choroidal measurements of the 


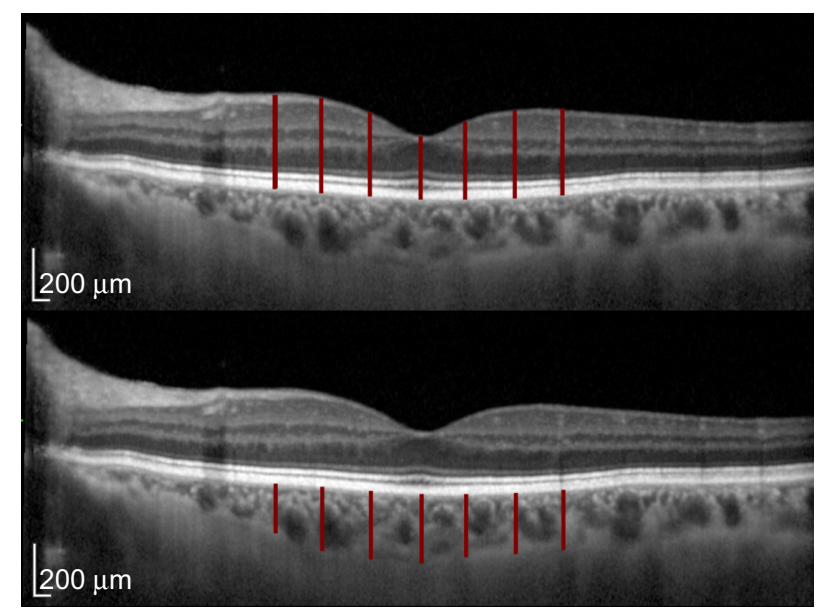

Figure I Retinal and choroidal thickness measurements. Using the calipers provided by the Spectralis ${ }^{\circledR}$ Heidelberg ${ }^{\circledR}$ software, manual retinal macular thickness measurements were performed at seven different locations centered on the fovea, $500 \mu \mathrm{m}$ apart (top). A mean retinal thickness value was obtained from these measurements. On the same locations used to measure the retinal thickness, manual choroidal measurements were also performed using the calipers, and a mean choroidal thickness was obtained (bottom). Measurements were performed on both horizontal and vertical scans.

peripapillary area were performed by manually changing the automatic detection of the retinal nerve fiber layer of the peripapillary area to the choroidal limits (the outer limit of the retinal pigment epithelium and the choroidal-scleral junction). The software then performed the measurements automatically. The measurements obtained were mean peripapillary choroidal thickness, and the mean choroidal thickness of the temporal, superior temporal, superior nasal, nasal, inferior nasal, and inferior temporal segments (Figure 2). Changes in thickness in the macular retina, in the submacular choroid, and in the peripapillary choroid were analyzed.

The surgical procedure was similar for all patients. All cataract surgeries were performed by phacoemulsification
(Infiniti Vision System, Alcon, Fort Worth, TX, USA) with acrylic intraocular lens implantation in the capsular bag. No intraoperative complications were reported. Postoperative medication was the same for all cases and consisted of dexamethasone, flurbiprofen, and ofloxacin eyedrops four times daily for 3 weeks.

\section{Statistical analysis}

Statistical analysis was performed with PASW Statistics (version 18.0 for Mac; IBM Corporation, Chicago, IL, USA). Preoperative and postoperative parameters were compared using paired two-tailed $t$-tests.

\section{Results}

Fourteen eyes from 14 patients were included in the study. Of the 14 patients, eight were male. Their mean age was 76 (median 75.5, range 69-83) years. Before surgery, mean retinal thickness was $308.77 \pm 14.69 \mu \mathrm{m}$ in vertical scans and $304.49 \pm 15.37 \mu \mathrm{m}$ in horizontal scans. Mean choroidal thickness was $238.63 \pm 76.12 \mu \mathrm{m}$ in vertical submacular scans, $239.28 \pm 79.08 \mu \mathrm{m}$ in horizontal submacular scans, and mean peripapillary choroidal thickness was $114.08 \pm 54.07 \mu \mathrm{m}$.

There were no intraoperative complications in the study patients. None of the studied patients developed clinically significant macular edema (Irvine-Gass syndrome) in the postoperative period.

After cataract surgery, there was a statistically significant increase in mean macular thickness one week after surgery in the horizontal scans $(+3.45 \pm 4.59 \mu \mathrm{m} ; P=0.015)$ and an even greater increase in both the mean horizontal $(+8.67 \pm 6.75 \mu \mathrm{m}$ $; P<0.001)$ and mean vertical $(+8.80 \pm 7.07 ; P=0.001)$ scans one month after surgery (see Tables 1 and 2 ).
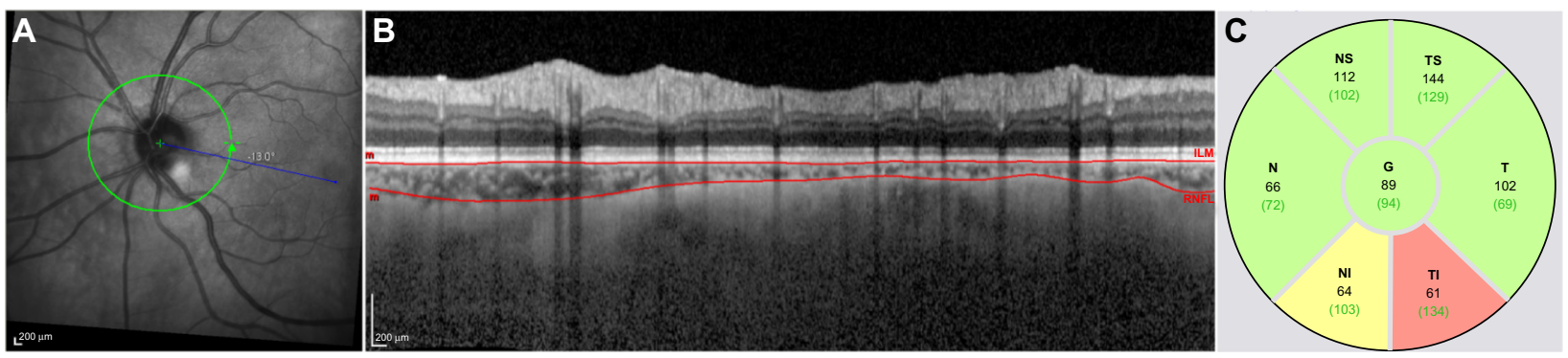

Figure 2 Peripapillary choroidal thickness measurements. Peripapillary SD-OCT scans were performed using the EDI mode (A). The automatic detection of the internal limiting membrane and retinal nerve fiber layer were manually changed so that they would correspond to the external border of the retinal pigment epithelium and the external limit of the choroid respectively (B). Automatic readings of the choroidal thickness were obtained in the quadrants provided by the Spectralis ${ }^{\circledR}$ Heidelberg ${ }^{\circledR}$ software (C). Choroidal thickness values are the numbers in black. The numbers in brackets and the color-coding refer to the normative database for RNFL evaluation of the Spectralis Heidelberg and are therefore irrelevant for the results.

Abbreviations: EDI, enhanced depth imaging; SD-OCT, spectral domain optical coherence tomography; RNFL, retinal nerve fiber layer; G, general; N, nasal; NS, nasal superior; TS, temporal superior; T, temporal; TI, temporal inferior; NI, nasal inferior. 
Table I Mean change in retinal and choroidal thickness in horizontal macular scans

\begin{tabular}{llll}
\hline & $\begin{array}{l}\text { Preoperative } \\
\text { horizontal }\end{array}$ & $\begin{array}{l}\text { Week I } \\
\text { horizontal }(\boldsymbol{P})\end{array}$ & $\begin{array}{l}\text { Month I } \\
\text { horizontal }(\boldsymbol{P})\end{array}$ \\
\hline Retinal & $304.49 \pm 15.37$ & $+3.45 \pm 4.59$ & $+8.67 \pm 6.75$ \\
thickness & & $(0.015)$ & $(0.000)$ \\
Choroidal & $239.28 \pm 79.08$ & $-1.27 \pm 37.17$ & $-9.11 \pm 39.59$ \\
thickness & & $(0.90)$ & $(0.41)$ \\
\hline
\end{tabular}

Notes: Results show the mean \pm standard deviation $(n=\mid 4)$; all measurements are in $\mu \mathrm{m}$.

However, there were no statistically significant changes in choroidal thickness one month after cataract surgery (Tables 1-3). This was true for both the choroidal submacular scans and the choroidal peripapillary scans. In the horizontal choroidal scans, a tendency towards a decrease in choroidal thickness was observed, but this failed to reach statistical significance $(-9.11 \pm 39.59 \mu \mathrm{m} ; P=0.41)$. In the peripapillary scans, there was a statistically significant increase in choroidal thickness in the superonasal and inferotemporal quadrants at one week. However, these changes were not significant one month after surgery (Table 3 ).

\section{Discussion}

Our results confirm previous findings that phacoemulsification surgery causes slight increases in macular thickness one month after surgery. ${ }^{6-10}$ These changes in macular thickness eventually return to normal after $2-6$ months. ${ }^{6,8}$ The changes in macular thickness seem to be induced by the inflammatory insult of surgery itself. Prostaglandins released during surgery play an important role in the development of postoperative cystoid macular edema and may also play an important part in the increases in macular thickness documented by OCT. ${ }^{5,21}$ This has led to the widespread use of topical steroidal and nonsteroidal anti-inflammatory drugs in the postoperative period of cataract surgery because these agents decrease the incidence of Irvine-Gass syndrome. As is current medical

Table 2 Mean change in retinal and choroidal thickness in vertical macular scans

\begin{tabular}{llll}
\hline & $\begin{array}{l}\text { Preoperative } \\
\text { vertical }\end{array}$ & $\begin{array}{l}\text { Week I } \\
\text { vertical }(P)\end{array}$ & $\begin{array}{l}\text { Month I } \\
\text { vertical }(P)\end{array}$ \\
\hline Retinal & $308.77 \pm I 4.69$ & $+1.69 \pm 4.18$ & $+8.80 \pm 7.07$ \\
thickness & & $(0.17)$ & $(0.00 \mathrm{I})$ \\
Choroidal & $238.63 \pm 76.12$ & $+0.47 \pm 25.8 \mathrm{I}$ & $+4.2 \mathrm{I} \pm 20.23$ \\
thickness & & $(0.95)$ & $(0.47)$ \\
\hline
\end{tabular}

Notes: Results show the mean \pm standard deviation $(n=14)$; all measurements are in $\mu \mathrm{m}$.
Table 3 Mean change in peripapillary choroidal thickness one week and one month after uncomplicated phacoemulsification

\begin{tabular}{|c|c|c|c|}
\hline $\begin{array}{l}\text { Peripapillary } \\
\text { choroid }\end{array}$ & Preoperative & Week I (P) & Month I $(P)$ \\
\hline Mean & I| $4.08 \pm 54.07$ & $\begin{array}{l}+6.64 \pm 9.31 \\
(0.040)\end{array}$ & $\begin{array}{l}+3.25 \pm 11.80 \\
(0.36)\end{array}$ \\
\hline Temporal & II $7.85 \pm 57.60$ & $\begin{array}{l}+4.00 \pm 12.02 \\
(0.30)\end{array}$ & $\begin{array}{l}+3.17 \pm 14.92 \\
(0.48)\end{array}$ \\
\hline Superotemporal & $133.08 \pm 63.92$ & $\begin{array}{l}+7.64 \pm 17.00 \\
(0.17)\end{array}$ & $\begin{array}{l}+5.92 \pm 16.52 \\
(0.24)\end{array}$ \\
\hline Superonasal & $134.23 \pm 63.40$ & $\begin{array}{l}+13.27 \pm 17.83 \\
(0.033)\end{array}$ & $\begin{array}{l}+1.67 \pm 11.56 \\
(0.63)\end{array}$ \\
\hline Nasal & || $15.08 \pm 6 \mid .32$ & $\begin{array}{l}+4.18 \pm 6.40 \\
(0.055)\end{array}$ & $\begin{array}{l}+2.00 \pm 17.07 \\
(0.69)\end{array}$ \\
\hline Inferonasal & $92.46 \pm 46.33$ & $\begin{array}{l}+2.91 \pm 21.07 \\
(0.66)\end{array}$ & $\begin{array}{l}+3.33 \pm 15.99 \\
(0.49)\end{array}$ \\
\hline Inferotemporal & $88.31 \pm 50.67$ & $\begin{array}{l}+|1.18 \pm| 1.47 \\
(0.009)\end{array}$ & $\begin{array}{l}+4.08 \pm 14.30 \\
(0.34)\end{array}$ \\
\hline
\end{tabular}

Notes: Results show the mean \pm standard deviation $(n=\mid 4)$; all measurements are in $\mu \mathrm{m}$.

practice, these anti-inflammatory agents were used in all our patients, blunting the inflammatory insult caused by the surgery. At this moment, we are not able to study the effect of phacoemulsification on retinal and choroidal morphology in patients who are not treated with topical nonsteroidal anti-inflammatory drugs and steroids because this would unacceptably increase their risk of developing Irvine-Gass syndrome. Therefore, the true effect of phacoemulsification on choroidal thickness cannot be evaluated. However, studying choroidal morphology in patients who do develop this syndrome, despite postoperative anti-inflammatory prophylaxis, may help to understand the possible choroidal changes induced by phacoemulsification.

In the majority of surgical cases, the inflammatory insult of phacoemulsification is not enough to cause pathologic macular or choroidal changes that significantly lower vision. Nagy et $\mathrm{al}^{22}$ have shown that the increase in retinal macular thickness is less pronounced in patients submitted to femtosecond-assisted cataract surgery and that the increase in macular thickness is mostly dependent on an increase in thickness of the outer nuclear layer. They postulated that this could be the result of less anterior segment manipulation during surgery and a consequent lower release of prostaglandins inside the eye. Lobo et al have shown that the increase in macular thickness is accompanied by an increase in localized fluorescein leakage from the retina into the vitreous due to a breakdown of the blood-retinal barrier. ${ }^{6}$ Animal studies have shown that a surgical insult can lead to a breakdown of both the internal and external blood-retinal barrier. ${ }^{14}$ However, our study shows that despite the changes that have been 
described at the retinal pigment epithelium level,,${ }^{14}$ changes in macular thickness are not accompanied by significant changes in submacular choroidal thickness and only cause slight changes in peripapillary choroidal thickness in the first week after surgery. This shows that the choroidal response is similar at different locations of the posterior pole. Even though in animal models cataract surgery leads to expression of inflammatory markers in the choroid, ${ }^{13}$ this inflammation is unable to produce significant changes in choroidal thickness as measured by EDI SD-OCT. Diffuse choroidal thickening is well known and was detected by ultrasound in the previous century in several intraocular inflammatory conditions, including uveitis, post-surgical situations, and ocular trauma. ${ }^{23}$ However, it seems that the inflammation and trauma induced by phacoemulsification is not sufficient to cause choroidal thickening that can be measured with a more sensitive imaging method (EDI SD-OCT). However, it is important to state that changes at the level of the choriocapillaris, changes in choroidal blood flow, and even in the production of inflammatory cytokines cannot be assessed by this imaging method. It is plausible that changes at the cellular level may participate in the mechanisms that lead to the increase in retinal thickness.

The measured changes in retinal thickness appear to be a dynamic pathophysiologic change that is not only related to optical changes that occur in the eye with intraocular lens implantation. These optical changes have also been shown to change retinal nerve fiber layer thickness measurements. ${ }^{11}$ However, the fact that macular thickness varies throughout the first postoperative month, when optical characteristics are kept stable, shows that changes in macular thickness do occur and are not exclusively an optical phenomenon. This has also been demonstrated in studies that have lasted longer (up to 6 months). ${ }^{8}$ Limitations to the study include the low number of patients included; however, we were able to detect and confirm the previously described retinal macular changes.

At present, the clinical significance of these slight macular thickness increases that are not accompanied by a choroidal volume change are not clear. Phacoemulsification is a very frequent procedure and the long-term effects on retinal and choroidal function are not known. However, the retinal changes observed with cataract surgery are not mirrored by an increase in choroidal thickness. In regular clinical practice, the inflammatory insult caused by phacoemulsification is strongly counteracted by postoperative topical anti-inflammatory treatment. However, even with this kind of therapy, surgery still induced changes in retinal thickness probably caused by a breakdown in the internal blood-retinal barrier; importantly, these inflammatory mechanisms seem to be incapable of causing significant morphologic choroidal changes.

\section{Disclosure}

The authors report no conflicts of interest in this work.

\section{References}

1. Jaffe GJ, Burton TC, Kuhn E, Prescott A, Hartz A. Progression of nonproliferative diabetic retinopathy and visual outcome after extracapsular cataract extraction and intraocular lens implantation. Am J Ophthalmol. 1992;114(4):448-456.

2. Chew EY, Benson WE, Remaley NA, et al. Results after lens extraction in patients with diabetic retinopathy: Early Treatment Diabetic Retinopathy Study report number 25. Arch Ophthalmol. 1999;117(12):1600-1606.

3. Gass JD, Norton EW. Cystoid macular edema and papilledema following cataract extraction. A fluorescein fundoscopic and angiographic study. Arch Ophthalmol. 1966;76(5):646-661.

4. Irvine SR. A newly defined vitreous syndrome following cataract surgery. Am J Ophthalmol. 1953;36(5):599-619.

5. Kim SJ, Flach AJ, Jampol LM. Nonsteroidal anti-inflammatory drugs in ophthalmology. Surv Ophthalmol. 2010;55(2):108-133.

6. Lobo CL, Faria PM, Soares MA, Bernardes RC, Cunha-Vaz JG. Macular alterations after small-incision cataract surgery. J Cataract Refract Surg. 2004;30(4):752-760.

7. Biro Z, Balla Z, Kovacs B. Change of foveal and perifoveal thickness measured by OCT after phacoemulsification and IOL implantation. Eye. 2008;22(1):8-12.

8. Vukicevic M, Gin T, Al-Qureshi S. Prevalence of optical coherence tomography-diagnosed postoperative cystoid macular oedema in patients following uncomplicated phaco-emulsification cataract surgery. Clin Experiment Ophthalmol. 2012;40(3):282-287.

9. Sourdille P, Santiago PY. Optical coherence tomography of macular thickness after cataract surgery. J Cataract Refract Surg. 1999;25(2):256-261.

10. von Jagow B, Ohrloff C, Kohnen T. Macular thickness after uneventful cataract surgery determined by optical coherence tomography. Graefes Arch Clin Exp Ophthalmol. 2007;245(12):1765-1771.

11. Kok PH, van den Berg TJ, van Dijk HW, et al. The relationship between the optical density of cataract and its influence on retinal nerve fibre layer thickness measured with spectral domain optical coherence tomography. Acta Ophthalmol. 2013;91(5):418-424.

12. Dada T, Behera G, Agarwal A, Kumar S, Sihota R, Panda A. Effect of cataract surgery on retinal nerve fiber layer thickness parameters using scanning laser polarimetry (GDxVCC). Indian J Ophthalmol. 2010;58(5):389-394.

13. $\mathrm{Xu} \mathrm{H,} \mathrm{Chen} \mathrm{M,} \mathrm{Forrester} \mathrm{JV,} \mathrm{Lois} \mathrm{N.} \mathrm{Cataract} \mathrm{surgery} \mathrm{induces}$ retinal pro-inflammatory gene expression and protein secretion. Invest Ophthalmol Vis Sci. 2011;52(1):249-255.

14. Tso MO, Shih CY. Experimental macular edema after lens extraction. Invest Ophthalmol Vis Sci. 1977;16(5):381-392.

15. Liu H, Demetriades AM, Xiao WH, Campochiaro PA, Vinores SA. Mouse model of post-surgical breakdown of the blood-retinal barrier. Curr Eye Res. 2004;28(6):421-426.

16. Margolis R, Spaide RF. A pilot study of enhanced depth imaging optical coherence tomography of the choroid in normal eyes. Am J Ophthalmol. 2009; 147(5):811-815.

17. Imamura Y, Fujiwara T, Margolis R, Spaide RF. Enhanced depth imaging optical coherence tomography of the choroid in central serous chorioretinopathy. Retina. 2009;29(10):1469-1473.

18. Fujiwara T, Imamura Y, Margolis R, Slakter JS, Spaide RF. Enhanced depth imaging optical coherence tomography of the choroid in highly myopic eyes. Am J Ophthalmol. 2009;148(3):445-450. 
19. Fong AH, Li KK, Wong D. Choroidal evaluation using enhanced depth imaging spectral-domain optical coherence tomography in VogtKoyanagi-Harada disease. Retina. 2011;31(3):502-509.

20. Falcao M, Vieira M, Brito P, Rocha-Sousa A, Brandao EM, Falcao-Reis FM. Spectral-domain optical coherence tomography of the choroid during valsalva maneuver. Am J Ophthalmol. 2012;154(4): 687-692. e681.

21. Miyake K, Ibaraki N. Prostaglandins and cystoid macular edema. Surv Ophthalmol. 2002;47 Supp1 1:S203-S218.
22. Nagy ZZ, Ecsedy M, Kovacs I, et al. Macular morphology assessed by optical coherence tomography image segmentation after femtosecond laser-assisted and standard cataract surgery. J Cataract Refract Surg. 2012;38(6):941-946.

23. Jalkh AE, Avila MP, Trempe CL, Schepens CL. Diffuse choroidal thickening detected by ultrasonography in various ocular disorders. Retina. 1983;3(4):277-283.

\section{Publish your work in this journal}

Clinical Ophthalmology is an international, peer-reviewed journal covering all subspecialties within ophthalmology. Key topics include: Optometry; Visual science; Pharmacology and drug therapy in eye diseases; Basic Sciences; Primary and Secondary eye care; Patient Safety and Quality of Care Improvements. This journal is indexed on

\section{Dovepress}

PubMed Central and CAS, and is the official journal of The Society of Clinical Ophthalmology (SCO). The manuscript management system is completely online and includes a very quick and fair peer-review system, which is all easy to use. Visit http://www.dovepress.com/ testimonials.php to read real quotes from published authors. 